\title{
THE ELECTROFORMING OF GOLD AND ITS ALLOYS
}

\author{
Anselm T. Kuhn * \& Leslie V. Lewis ** \\ * Faculty of Science \& Technology, Harrow College, Harrow HA1 3TP, U.K. \\ ** B.J.S. Electroforming Ltd., London NW6, U.K.
}

\begin{abstract}
Electroforming is an area of gold technology which is of growing interest to workers in fields as diverse as gold jewellery manufacturing and dentistry. In this short overall review of the subject, the authors focus on developments in both applications and techniques over the past two decades.
\end{abstract}

Electroforming can be described as a manufacturing process based on the electrodeposition of a metal. Unlike electroplating, however, where the deposited metal covers a substrate, in electroforming, at the end of the deposition process, that substrate (which is known as the mandrel), is removed, leaving the electrodeposit as an object in its own right. Thus electroforming, though it superficially resembles electroplating, is in fact a far more advanced technology. Not only is the preparation of the mandrels a complex procedure, but also many of the difficulties inherent in electrodeposition, such as current distribution and the incidence of internal stress, become critically obvious in electroforming, whereas in electroplating, this might not have been the case. For every hundred companies in the electroplating industry, perhaps one might include electroforming among their activities.

In many ways, gold and its alloys might be thought to be ideal candidates for electroforming. The ability of the technology to produce sections far thinner than is possible by casting, coupled with the near-perfect reproduction of surface detail, are two major advantages in manufacture of decorative gold objects. In fact, the electroforming of gold and its alloys has, until the last five years or so, been little more than a curiosity and only recently has there been significant commercial activity in this area. Thus the standard reference work on electroforming by Spiro [1] published in 1971 barely mentions the subject.

The reason for this can be largely attributed to lack of development of suitable electrolytes for electroforming of gold. Whereas gold-plating has long been established, attempts to build up thicker gold deposits met with failure, those deposits being prone to cracking. In the last few years, this situation has improved, and solutions capable of yielding thick deposits of gold and at the same time displaying reasonable stability, have been developed. This success has prompted further research into solutions for electroforming of gold alloys which has already been partly successful, but it is clear that further developments will be announced before long.

\section{Solutions for Gold Electroforming}

Most solutions for the electroforming of gold, as for its plating, are based either on cyanides, sulphites, chlorides or a combination of these. Citrate solutions, though used for gold plating, appear not to have found favour for electroforming. Some suggested solution compositions for electroforming of gold are quoted by Reid and Goldie [2]. However, as far as the present authors are aware, these are now of historical interest and are not used in practice. For obvious reasons, there is a degree of proprietary secrecy covering those solutions which are in commercial use. In spite of this, some interesting information is available.

Rogers [3] has described a bath containing $14.1 \mathrm{~g} / \mathrm{l}$ potassium gold cyanide, 18.31 gotassium cyanide, $14.1 \mathrm{~g} / 1$ potassium carbonate and $11.4 \mathrm{~g} / 1$ boric acid. Operated at a current density of $3.2 \mathrm{~A} / \mathrm{dm}^{2}$ at $65^{\circ} \mathrm{C}$ with agitation, the deposition rate is $100-125 \mu \mathrm{m} / \mathrm{h}$. He points out that owing to excessive rate of water loss under these conditions, it is preferable to work at $60^{\circ} \mathrm{C}$ to give a deposition rate of $75 \mu \mathrm{m} / \mathrm{h}$. This results in a virtual halving of cathode ef- 


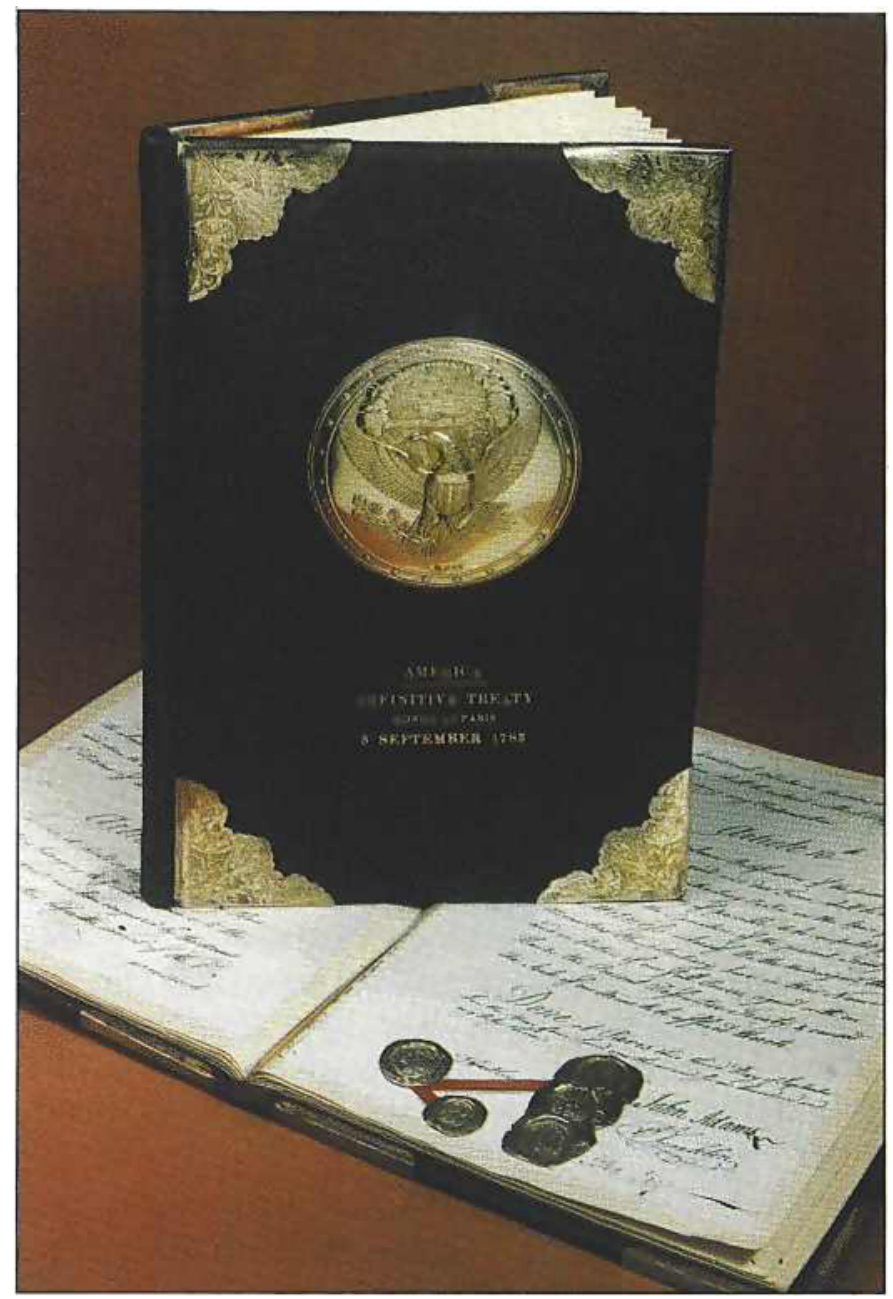

Fig. 1 Hand bound copy of the American Treaty of Independence with seals, cornerpieces and skippet cover insert electroformed in 24 carat gold (courtesy B.J.S. Electroplating Co.) ficiency in the latter case. Too high a current density gives a brownish burnt effect.

The coronet illustrated in Figure 5 is stated to have been formed in a neutral ( $\mathrm{pH}=6.5$, no free cyanide) gold solution containing not less than $28 \mathrm{~g} / \mathrm{l}$ and up to $36 \mathrm{~g} / \mathrm{l}$ gold, and based on gold potassium cyanide neutralised with phosphate.

Sulphite gold electroforming solutions are based on sodium, sodium and ammonium or potassium ions, and use arsenic as grain refiner. DOS 2249658 (1972) describes the electroforming of gold layers up to $600 \mu \mathrm{m}$ thick, using such solutions.

\section{The Electroforming of Gold Alloys}

In the main, there are two approaches to the electroforming of gold alloys, based on a). simultaneous and b). sequential deposition. There are also reports of procedures which do not fall into either category.

\section{Simultaneous Deposition}

Here, the alloy is electroformed by the simultaneous electrodeposition of the two, and in some cases three, metals in question. The main problem with this approach is that found in most cases of electrodeposition of alloys, namely that the composition of the deposited alloy is a function not only of the solution composition, but also of current density and temperature. In a manufacturing situation, an error in one direction results in the (wasteful) deposition of a higher carat alloy than that specified, while in the other direction lies the danger of producing substandard alloy. These problems are further multiplied when three-dimensional articles are to be formed, in that the throwing power of the individual metals differs.

The first commercial process claiming to overcome at least some of these difficulties was launched by O.M.I. In this, the deposition process is controlled by a computer, which regulates bath temperature to better than $1^{\circ} \mathrm{C}$ as well as using input from sensors to maintain the concentrations of each of the metal ions by actuating dosing pumps, The computer also logs total charge passed and takes into account the surface area of the work being

Fig. 28 carat gold jewellery electroformed with the Auruna process (courtesy Degussa) 
formed. The 14 or 18 carat alloys which are so formed (copper and cadmium being the other components) require subsequent heat-treatment in an inert atmosphere, and the overall process in one calling for a major capital investment. The composition of the electrolytes used in this process is not stated, though Swiss Pat. CH 529843 may indicate the underlying thinking.

More recently, a German firm, Degussa, has announced a somewhat similar process. At present, this is capable of producing only 8 and 9 carat alloys with silver as a second component, though 14 and 18 carat solutions are said to be under development. A significant advantage of the Degussa process appears to be the absence of any need for heat treatment. Additionally, the alloy composition appears to be less sensitive to variations in deposition parameters. Degussa suggest that an over-caratage of 1 point is sufficient to eliminate any local under-caratage, which would otherwise cause the item to fail a hallmarking test. An interesting point is the recommendation by these manufacturers that, after forming, a thin flash of pure gold be deposited. This suggestion is an indication that variations in colour can arise, presumably as a result of imperfect current distribution.

An alternative to the true simultaneous deposition of a ternary alloy is described in Japanese Pat. 59/80788 A2. The electrolyte contains the three metals gold, silver and copper. However, the rate of stirring is cyclically increased and reduced. At high stirring rates, the deposit is about $95 \%$ Au-Ag (of which $80-90 \%$ is $\mathrm{Au}$ ), while at low stirring rates, the deposit is about $95 \% \mathrm{Au}-\mathrm{Cu}$ (of which $50-70 \%$ is $\mathrm{Au}$ ). Each such layer is about $0.1 \mu \mathrm{m}$ thick and the process is completed until the required thickness has been reached. After this, the work is heat-treated.

Moving somewhat away from alloys to the subject of co-deposits, Japanese Pat. JP 53/6935 discloses the manufacture of electrical contacts made of electroformed Au-W. Tungsten particles of ca $0.5 \mu \mathrm{m}$ diameter are coated with electroless Pd and then dispersed in the electroform-

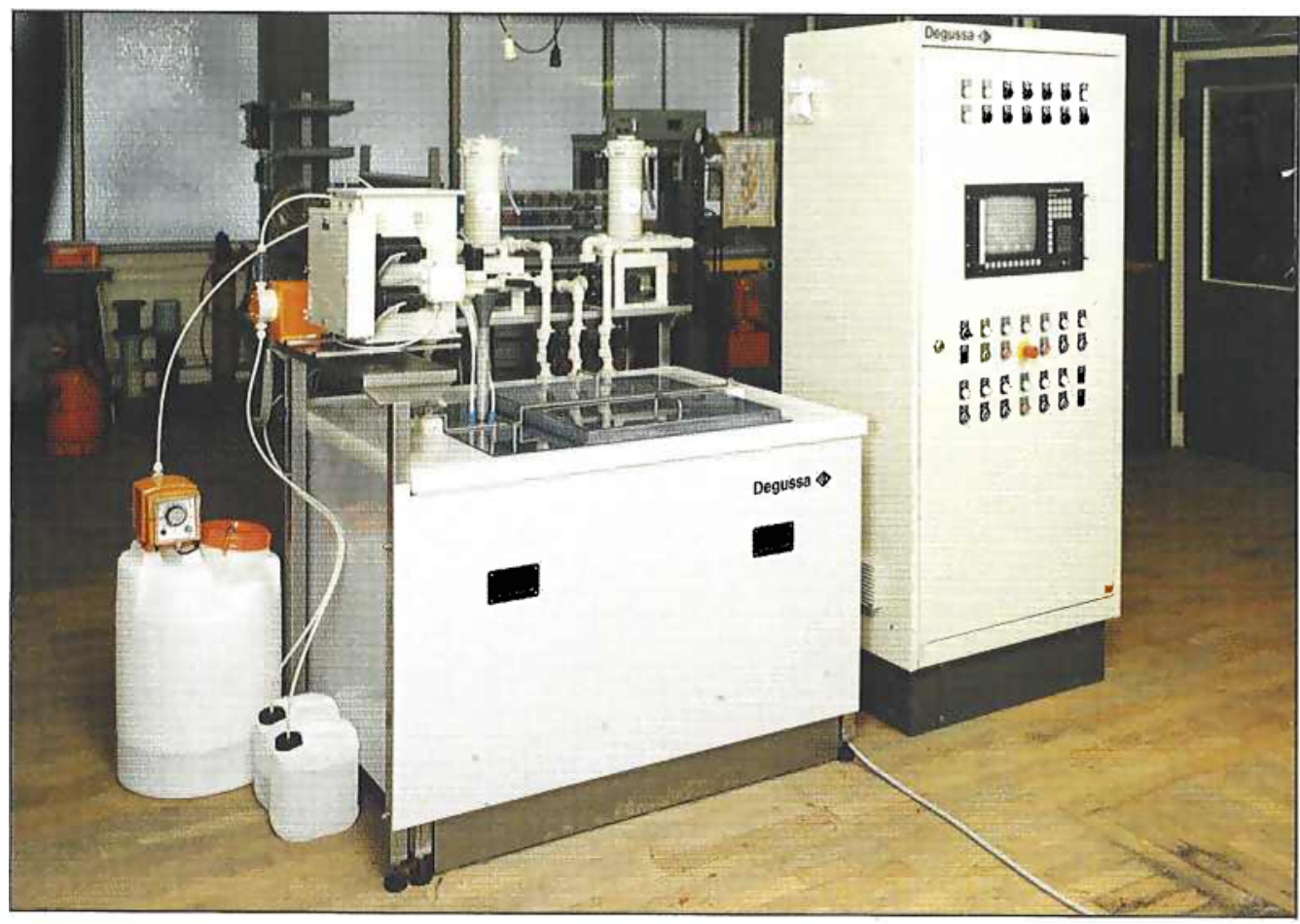

Fig.3 Computer-controlled gold alloy electroforming plant (courtesy Degussa) ing bath. The resulting composite contained $13 \mathrm{wt} . \% \mathrm{~W}$.

\section{Sequential Deposition}

In this approach, the alloy is formed by deposition of each of the metals of the ally in turn. This cycle may take place once only or may be repeated several times so that the deposit consists of numerous discrete layers of the different metals. Following this, the deposit is heat-treated so that interdiffusion occurs, the result being a homogeneous material.

\section{Technology}

Gold itself may be electroformed in simple and conventional electroplating plant. An accurate amp-minute meter, highly desirable for electroplating of gold, is arguably less important in electroforming where direct thickness measurement is easier. In US Pat. 4288298 , Rogers describes a gold electroforming tank which, though primarily intended for forming dental crowns up to $200 \mu \mathrm{m}$ thickness, could equally well be used for other similar small items. It consists of a tank divided into three compartments, one of which is the main electroforming section, one being for pumping and filtration, the third for solution storage. Facing the cathodic plane, on which are set a number of the trown mandrels, is the anodic plane, into which are set a number of stainless steel baskets. Sheet 
gold is inserted into these baskets, to serve as an anode and provision is made for switching in or out of circuit, some of these baskets, to create the appropriate anode-cathode symmetry. Elsewhere (US Pat. 3997 637), the same author indicates the use of pumped electrolyte being directed by a fine tube to the recesses of concave shapes being electroformed.

Although gold anodes have been used for electroforming of the pure metal, current practice is almost invariab-

ly based on the use of platinised titanium anodes. Stainless steel has also been used but is not recommended.

\section{Equipment for Electroforming of Gold Alloys}

The two firms previously mentioned, each supply computer-controlled plants for the electroforming of gold alloys.

In one of these designs, the work is mounted on a rotating 'carousel' jig. There are two gold anodes, one inside

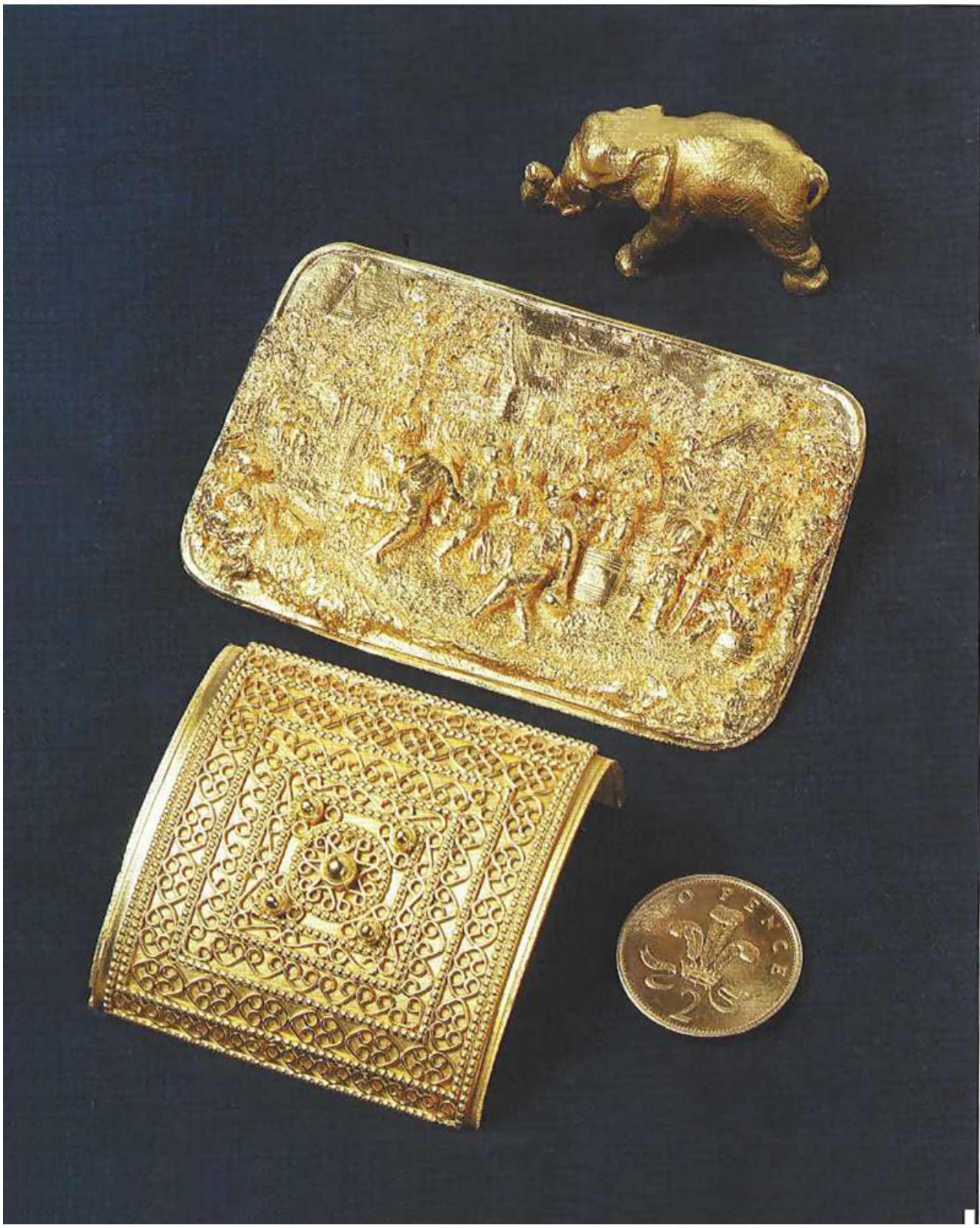

Fig. 4 Selection of 24 carat gold electroforms including the scabbard-top of an Arabian dagger, a gold elephant, and the lid of a small box showing a country scene and one outside the carousel. Each piece of work (and there may be over 100 mounted in this jig) thus passes continuously between the two anodes, so ensuring the best possible metal distribution. The computer carries out the functions previously mentioned and controls the bath temperature, to a precision of $0.1^{\circ} \mathrm{C}$. It is also connected to an electronic balance, the purpose of which is explained below.

As with the electrodeposition of almost all alloys, the composition of the deposit is a function of the current density. This implies, in the production of defined carat alloys, that the surface area of the work being formed must be known. Furthermore, especially in the case of smaller pieces, the surface area will grow as metal is deposited on the surface. The computer is interfaced with the rectifier to allow a constant current density to be maintained. During the electroforming, the work is weighed four times. On each of these occasions, great care must be taken to first wash and then dry the work before weighing. The first weighing is made prior to any electroforming, the second after about $25 \%$ of 
the required deposit has been laid down, the third after some $50 \%$, and the final weighing is at the conclusion of the process. The computer calculates the weight gain in each case and compares it with the total charge passed, in ampere-minutes. Because gold is so much denser than the other metals in the alloy, this calculation allows an estimate of the alloy composition to be made and, depending on the result (too rich or too poor in gold), the computer automatically adjusts the current (and so the current density) to the plant. Other technical details are found in $[8,12]$.

\section{Power Supplies}

Almost all reports of gold electroforming employ DC current. In Japanese Pat. 58/130293 A2, the deposition is under potentiostatic control which is stated to give good results, a $150 \mu \mathrm{m}$ gold-silver alloy deposit showing little variation in composition. In US Pat. 4343 684, Lechtzin describes a long series of test experiments, in some of which periodic reverse current ( $60 \mathrm{~s}$ forward, ca 4 s reverse) was used, but the concludes there was not benefit and abandoned its use. In Swiss Pat. CH 529843 too, current reversal is used, the cathode:anode period being 5-10 to 1 . It is suggested that the amount of ripple on the D.C. affects the composition of the deposit and that by varying this ripple between 0.1 and $4 \%$, a degree of compositional control may be achieved. The early work of Gardam \& Tidswell [4] extolling the virtues of current interruption in the deposition of gold and its alloys, appears to have been largely overlooked.

Recognising the difficulties in obtaining thick and structurally-sound gold deposits, at least two workers have advocated the use of ultrasonics. Vrobel [5] found the permissible deposition current density to increase to $1.8 \mathrm{~A} / \mathrm{dm}^{2}$, corresponding to a deposition rate of $54 \mu \mathrm{m} / \mathrm{h}$. There was also an increase in the microhardness of the deposit to $220 \mathrm{~kg} / \mathrm{mm}^{2}$. A few years later, the same idea was expressed in US Pat. 3427 231. While Vrobel referred only to electroplating, the latter Pat.ent explicitly describes both plating and forming of gold. The authors of the Pat.ent claim that, under the ultrasonic field effect, current densities may be increased to ${ }^{\prime} 10 \mathrm{kA} / \mathrm{m}^{2}$ or indefinitely'. In fact, in their examples, a current density of ca $0.5 \mathrm{kA} / \mathrm{m}^{2}$ is used. They also claim that, under ultrasonic agitation, the need for both filtration and addition of organic agents is obviated.

\section{Physical Properties of Electroformed Gold and its Alloys}

Very little has been reported under this heading. Vrijhoef et al. [6] compare the properties of conventional gold

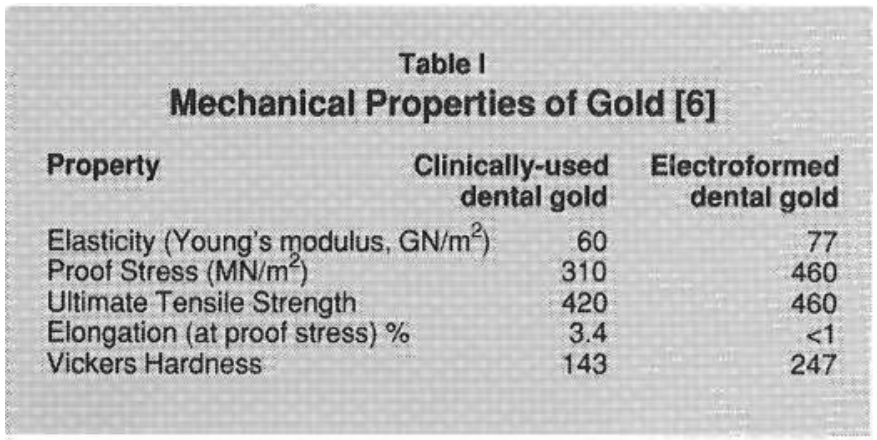

as used in dentistry with the electroformed metal. Table I is adapted from their paper and suggests that significant (and potentially most useful) differences are found.

An earlier paper on the physical and mechanical properties of electroformed $\mathrm{Au}-\mathrm{Cu}$ alloys in the range 65$90 \mathrm{wt} . \%$, is by Wiesner \& Distler [7] who used both flat sheet and tubular samples for their measurements. The strongest alloy is found at around the $75 \mathrm{wt} . \%$ composition, but the effects of heat-treatment (which is considered in some detail) can exert a considerable influence with $3 \mathrm{~h}$ at $350^{\circ} \mathrm{C}$, yielding substantially stronger specimens (UTS $=120 \mathrm{~kg} / \mathrm{mm}^{2}$ ) than those treated for this time at 400 or $450^{\circ} \mathrm{C}$. Interesting structural information is also given by these authors. Apart from these facts, Desthomas [8] gives the following information on gold electrodeposits: hardness, 220-300HV; density, 17; while in US Pat. 3427231 , Knoop hardness values of over 125 are mentioned. There are also sketches of the metallurgical structures of gold formed at several current densities.

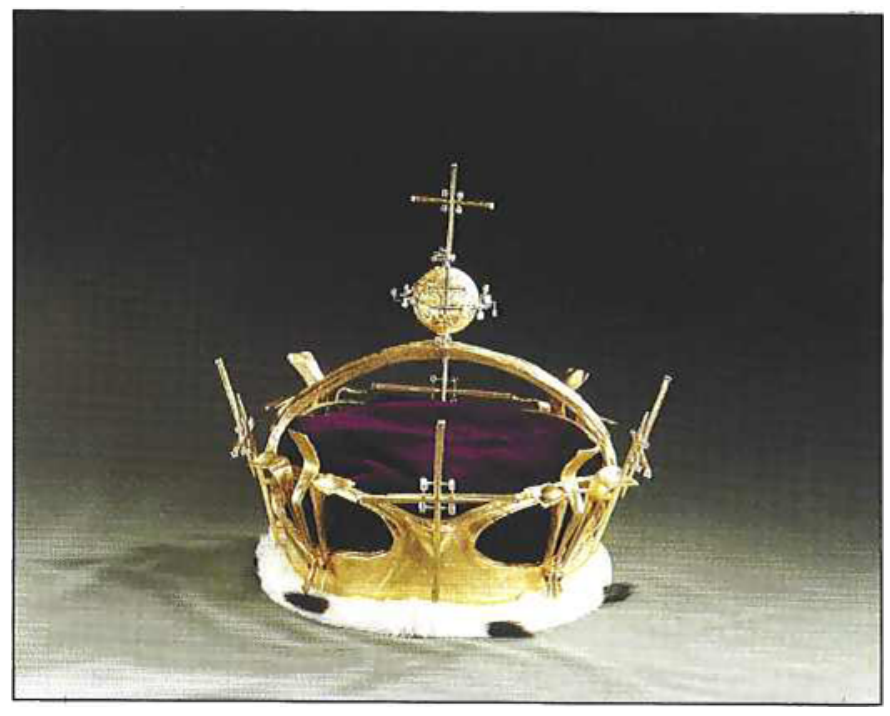

Fig.5 Coronet for the coronation of HRH the Prince of Wales (courtesy, Worshipful Company of Goldsmiths, London) 


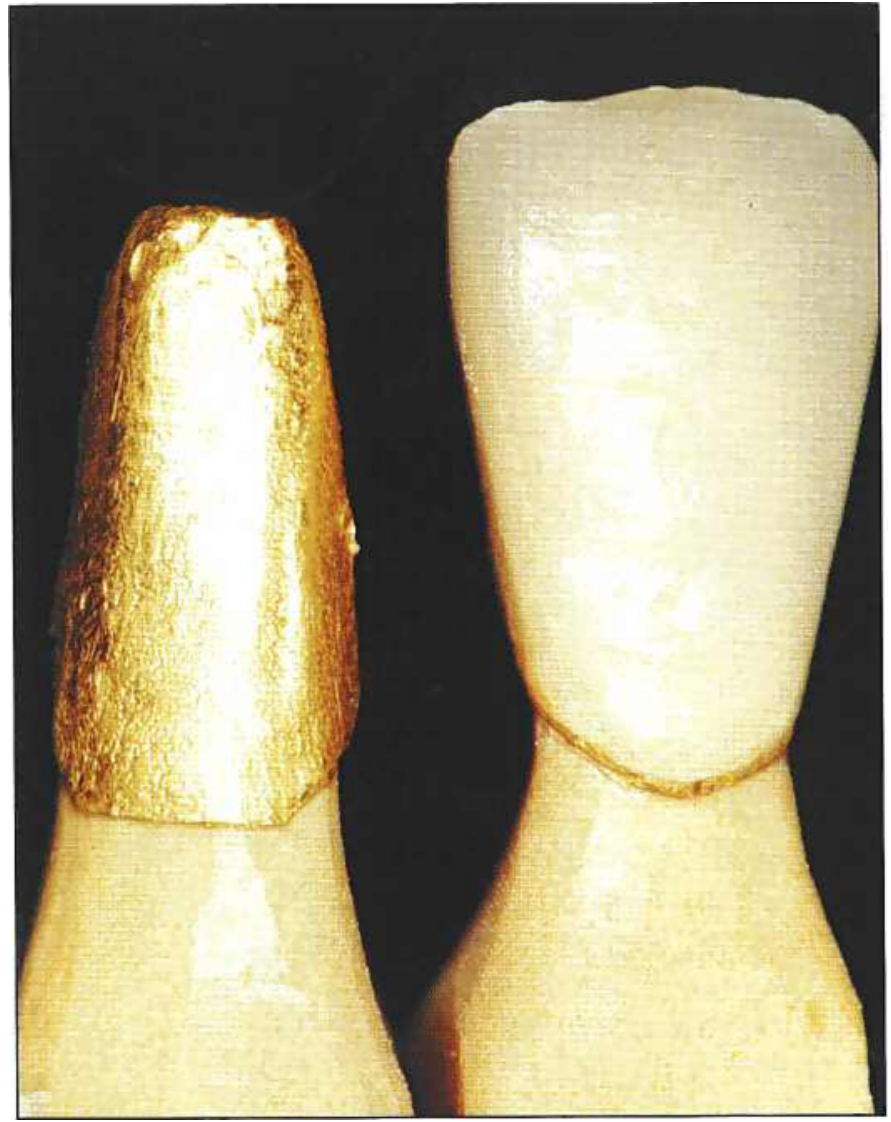

Fig. 6 Gold electroformed matrix on tooth preparation (left), and (right) the same after ceramic veneering (courtesy Dr O.W. Rogers)

\section{Applications of Electroforming to Gold and its Alloys}

The main applications of electroforming of gold and gold alloys can be grouped under the following headings: Jewellery and other Decorative, Dental, and Technical and Miscellaneous

\section{Jewellery and other Decorative Applications}

By far the most famous electroformed piece, is the Coronation Crown of H.R.H. the Prince of Wales, which was made in 24 carat gold by B.J.S Electroformers and Engelhard Ltd in 1967 from the design of Osman. The total weight of this single piece before trimming off, was in excess of $7 \mathrm{~kg}$, making it easily the largest gold electroform on record. The magnificence of this item has tended to overshadow the thousands of far smaller items made using the same technology. A number of patents describe specialised applications of electroforming. US Pat. 4464231 relates to the electroforming of miniature hollow gold spheres. These are formed using spherical plastic mandrels. After forming, the plastic is removed by making a tiny hole in the spheres and heating to volatilise it. The examples in the patent are based on successive deposition of copper, silver and gold which are then heated to form an alloy of gold.

UK Pat. App. GB 2167444 , extols the merits of electroforming for gold jewellery manufacture, suggests that the mechanical properties of the metal are better than those of wrought gold, but offers no data. It does embody the idea that gemstones, after embedding in soft gold, may be more securely held by a subsequent electroforming of gold above the setting metal.

A very old idea in electroforming is based on the use of flowers, leaves, insects or other naturally occurring objects as mandrels. By encasing these in electroformed gold, the beauty of their shape is retained but in a permanent and more durable form. In some cases, the organic matter involved is 'locked-in' by the electroforming. In UK Pat. App. 2031 024, this is not the case and the patent describes how a flower was electroformed in gold. The flower is then autoclaved for $2 \mathrm{~h}$ (temperature not stated) and after cooling, a jet of high-pressure water is forced through the stem end to eject the disintegrated organic matter.

Yet another application of decorative application of gold electroforming is related to watches. Three Japanese patents indicate the possible scope here. For example, Jap. Kokai Pat. 59/80788 A2 (to Seiko Watch Co.) covers the use of electroforming for 'external parts of watches' based on gold alloys.

\section{Dental Applications of Electroformed Gold}

The demands of restorative dentistry - the manufacture of jacket crowns or inlays, each one custom-fitted and of

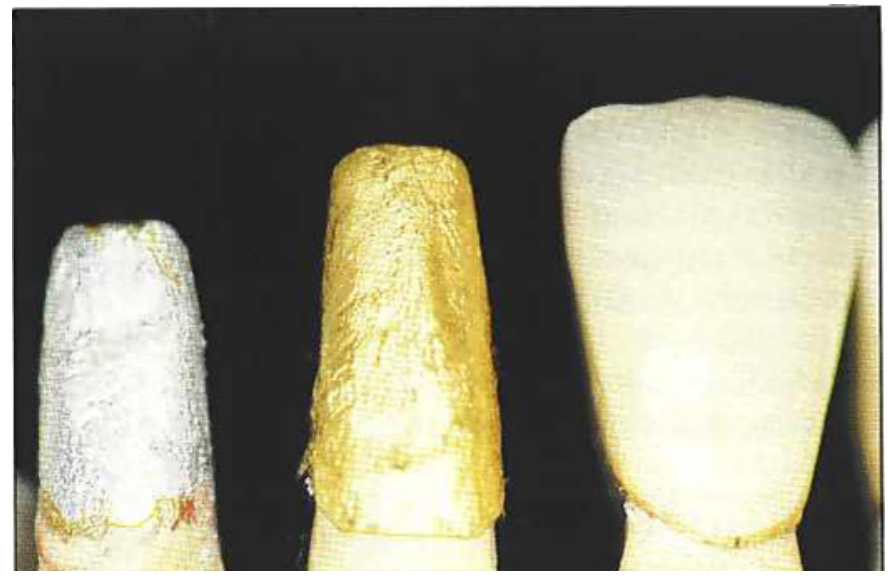

Fig. 7 Same as Figure 6, but also showing prepared tooth (left) (courtesy Dr O.W. Rogers) 


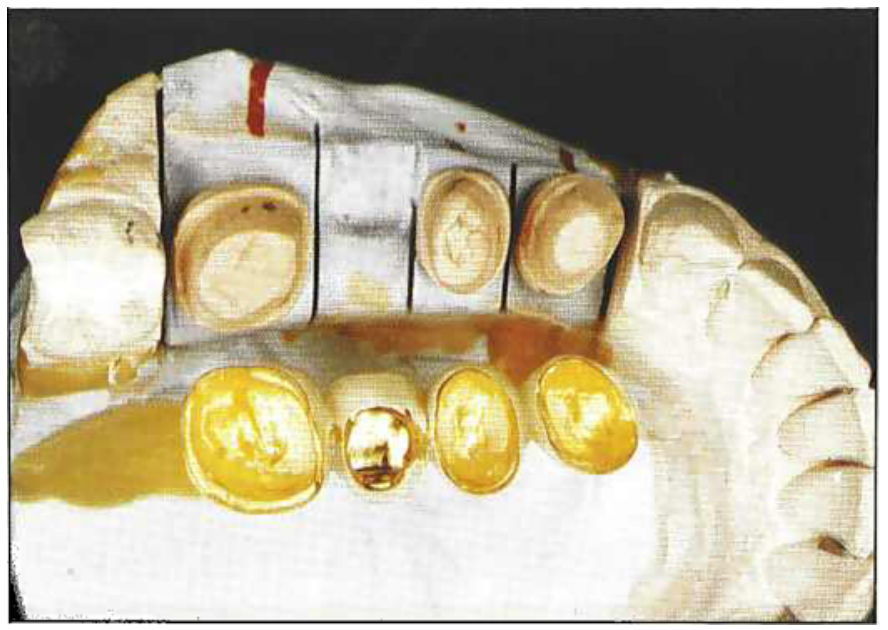

Fig. 8 Electroformed gold crowns with porcelain veneer. Top photo: interior of crowns, with plaster models from which they were formed; topright: crowns in place; lower right: electroformed gold inlay

a highly complex shape, with the additional requirement of thin sections, high mechanical strength and corrosion resistance and yet the lowest possible cost, explains why this is one of the oldest of the proposed applications of electroformed gold. And yet, in spite of some extremely promising results, it must be admitted that the dental profession has been slow to adopt the idea, perhaps because this is not a technology offered by the dental laboratories to which dentists have access. The most enthusiastic protagonist in all of this is Rogers [9], with at least half a dozen publications and patents on the subject. More recently, Vrijhoef and co-workers in the Netherlands have also advanced the subject [6] and it is clear from the work of both Rogers and of Vrijhoef et al. that they have been successful in taking their work from the laboratory to the point where it can and is being used by clinicians.

\section{Technical and Miscellaneous Applications of Gold Electroforming}

The main emphasis here seems to be on applications in the field of electronics, instrumentation and communications. Some of these are listed below:

$\begin{array}{ll}\text { X-ray photomasks } & \text { Jap 58/114427 A2 } \\ & \text { Jap 58/200535 A2 } \\ \text { Infra-red grid filters } & \text { Chanin [10] } \\ \text { Micrometer Scale }(50 \mu \mathrm{m}) & \text { Young \& Ogburn [11] } \\ \text { Bump circuitry } & \text { US Pat 4 125 441 }\end{array}$

The micrometer scale, which is manufactured by the US Bureau of Standards, is formed by alternate deposition of layers of nickel and gold which, because their thicknesses can be controlled and determined by the charge passed, may be used to calibrate electron microscopes.
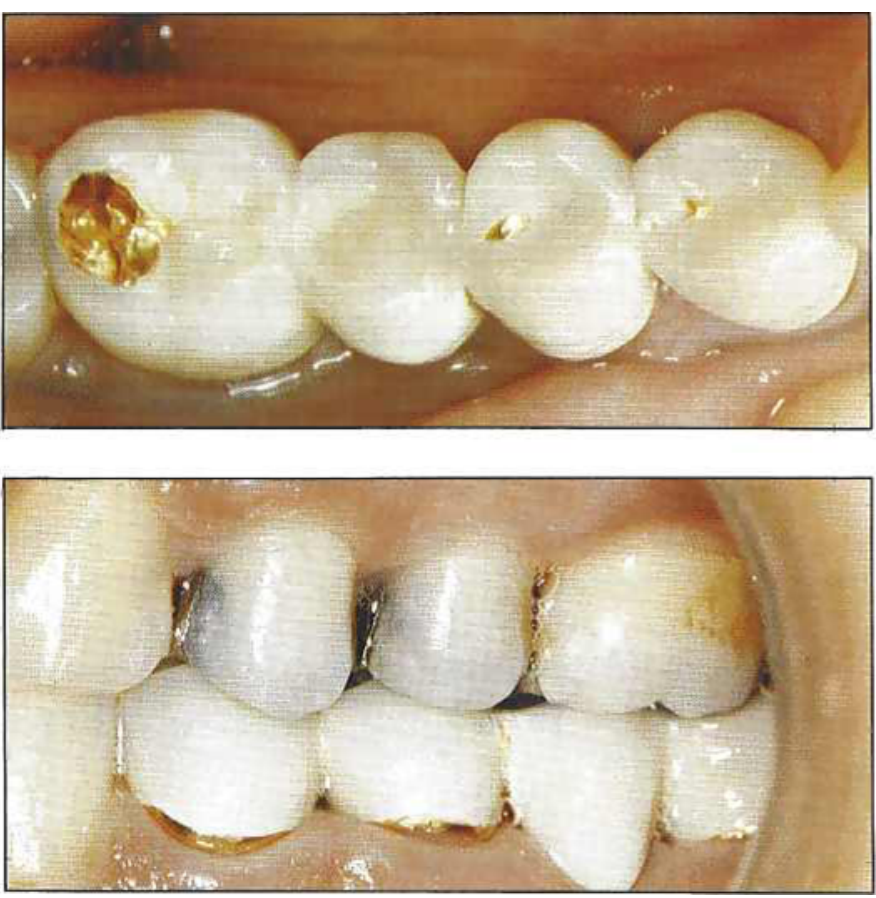

\section{Conclusion}

The authors are in no doubt that after a very slow start, the electroforming of gold and its alloys is a technology capable of considerable further development and that as this takes place, so will the scale of its use increase.

\section{References}

1 P. Spiro, Electroforming, Robert Draper, Teddington, 1971

2 F.H. Reid and W. Goldie, Gold Plating Technology, Electrochemical Publications, Ayr, 1974

3 O.W. Rogers, Austral. Dent. J., 1979, 24, 163-170 and 1977, 22, 371-372

4 G.E. Gardam and N.E. Tidswell, Trans. Inst. Metal Fin., $1954, \mathbf{3 1}, 418-425$

5 L. Vrobel, Trans. Inst. Metal Fin., 1966, 44, 161-164

6 M.M.A. Vrijhoef, A.J. Spanauf, H.H. Rengli, et al., Tijdschr. Oppervlaktetech. Mater., 1985, 29(4), 123126, (Chem. Abs. 103:92818u)

7 H.J. Wiesner and W.B. Distler, Plating, 1969, 56, 799-804

8 G. Desthomas, Tijdschr. Oppervlaktetech. Mater., 1984, 28, 92-95, 102;

idem., Aurum, 1983, (14), 19-26 and 1983, (15), 17-21

9 O.W. Rogers, Austr. Dent. J., 1976, 21(6), 479-487, 1980, 25, 205-208 and 1979, 24, 163-170

10 G. Chanin, Astrophys. Space Sci. Libr., 30 (Infra-red Det'n); Proc. 5th ESLAB/ESRIN Symp., 1971, 219224 (Chem. Abs. 83:18794k)

11 J.P. Young, F. Ogburn and D. Ballard, Plating, 1980, 78(8), 27-29

12 G. Desthomas, Galvanotechnik, 1986, 77(6), 1342-45 